\title{
A combination of a ribonucleotide reductase inhibitor and histone deacetylase inhibitors downregulates EGFR and triggers BIM- dependent apoptosis in head and neck cancer
}

\author{
Roland H. Stauber ${ }^{1, *}$, Shirley K. Knauer ${ }^{2, *}$, Negusse Habtemichael ${ }^{1}$, Carolin Bier $^{1}$, \\ Britta Unruhe ${ }^{2}$, Simona Weisheit ${ }^{3}$, Stephanie Spange ${ }^{3}$, Frank Nonnenmacher ${ }^{4}$, \\ Verena Fetz ${ }^{1}$, Torsten Ginter $^{3}$, Sigrid Reichardt ${ }^{3}$, Claus Liebmann $^{3}$, GünterSchneider ${ }^{5}$, \\ Oliver H. Krämer ${ }^{3, *}$ \\ ${ }^{1}$ Molecular and Cellular Oncology/Mainz Screening Center, University Hospital of Mainz, Germany \\ ${ }^{2}$ Institute for Molecular Biology, Centre for Medical Biotechnology (ZMB), University Duisburg-Essen, Germany \\ ${ }^{3}$ Institute of Biochemistry and Biophysics/Center for Molecular Biomedicine, Friedrich-Schiller-University Jena, Germany \\ ${ }^{4}$ Sanofi-Aventis Deutschland GmbH, Industriepark Hoechst, Germany \\ ${ }^{5}$ II. Medizinische Klinik, Technische Universität München, Germany \\ * Denotes equal contribution \\ Correspondence to: Oliver H. Krämer, email: oliver.kraemer@uni-jena.de
}

Roland H. Stauber, email: rstauber@uni-mainz.de

Shirley K. Knaver, email: shirley.knaver@uni-due.de

Keywords: BH3-only protein, chemotherapy resistance, hydroxyurea, oral cancer, tumor xenograft, valproic acid

Received: January 16, 2012, $\quad$ Accepted: January 25, 2012,

Published: January 28, 2012

Copyright: @ Stauber et al. This is an open-access article distributed under the terms of the Creative Commons Attribution License, which permits unrestricted use, distribution, and reproduction in any medium, provided the original author and source are credited.

\section{ABSTRACT:}

Head and neck squamous cell carcinomas (HNSCCs) are the sixth most common malignant neoplasm and more than $50 \%$ of patients succumb to this disease. HNSCCs are characterized by therapy resistance, which relies on the overexpression of anti-apoptotic proteins and on the aberrant regulation of the epidermal growth factor receptor (EGFR). As inherent and acquired resistance to therapy counteracts improvement of long-term survival, novel multi-targeting strategies triggering cancer cell death are urgently required. We investigated how induction of replicational stress by the ribonucleotide reductase inhibitor hydroxyurea (HU) combined with histone deacetylase inhibitors (HDACi) exerts anti-tumor activity. We treated HNSCC cell lines and freshly isolated tumor cells with HDACi, such as the clinically approved antiepileptic drug valproic acid (VPA), in combination with HU. Our data demonstrate that at clinically achievable levels VPA/HU combinations efficiently block proliferation as well as clonogenic survival, and trigger apoptosis of HNSCC cells. In the presence of VPA/HU, such tumor cells increase expression of the pro-apoptotic BCL-2 family protein BIM, independent of wild-type p53 signaling and in the absence of increased expression of the p53 targets PUMA and BAX. The pro-apoptotic activity of BIM in HNSCCs was found critical for tumor cell death; ectopic overexpression of BIM induced HNSCC apoptosis and RNAi-mediated depletion of BIM protected HNSCC cells from VPA/HU. Also, significantly elevated BIM levels $(p<0.01)$ were detectable in the apoptotic tumor centers versus proliferating tumor margins in HNSCC patients $(n=31)$, underlining BIM's clinical relevance. Importantly, VPA/HU treatment additionally reduces expression and cell surface localization of EGFR. Accordingly, in a xenograft mouse model, VPA/HU efficiently blocked tumor growth $(P<0.001)$ correlating with BIM induction and EGFR downregulation. We provide a molecular rationale for the potent anti-cancer activities of this drug combination. Our data suggest its exploitation as a potential strategy for the treatment of HNSCC and other tumor entities characterized by therapy resistance linked to dysregulated EGFR activation. 


\section{INTRODUCTION}

With a worldwide annual incidence of more than 640,000 cases, head and neck cancer is the sixth most common malignant neoplasm in humans $[1,2]$. The majority of head and neck squamous cell carcinoma (HNSCC) is induced by chronic exposure to a surplus of carcinogens enclosed in all forms of tobacco, synergized by heavy alcohol consumptions and/or is associated with oncogenic human papillomaviruses [3, 4]. HNSCC is characterized by local tumor aggressiveness, high rate of early recurrences and development of second primary carcinomas [3]. Loco-regional relapse after therapy is the major cause of death despite modern disease management strategies [5, 6]. Hence, long-term survival rates, especially for advanced HNSCC (30-40\%), have not improved significantly over the last decades $[3,6]$. Currently, EGFR-targeting agents, such as antibodies or tyrosine kinase inhibitors gained major clinical attention $[3,7]$. Despite encouraging developments, EGFR-directed therapies are effective only in a relatively small percentage of cancer patients underlining the need for additional combination treatment options [7-9].

Therapy resistance favoring recurring or advancedstage HNSCC mainly results from failure of the tumor cells to undergo chemoradiation-induced apoptosis $[1$, 3]. Particularly, the intrinsic or mitochondrial pathway of programmed cell death (PCD) plays an important role for killing cancer cells in response to various therapies, and is controlled by interactions among pro- and anti-apoptotic BCL-2 protein family members $[10,11]$. Pro-survival proteins like BCL-XL and BCL-2 inhibit apoptosis by binding and neutralizing the activities of the pro-apoptotic multidomain proteins $\mathrm{BAX}$ and $\mathrm{BAK}$ as well as the $\mathrm{BH} 3$ domain-only proteins BIM, BIK, NOXA, and PUMA [1012].

Overexpression of anti-apoptotic BCL-2 proteins and apoptosis inhibitors like Survivin plays a critical role for therapy resistance and overall survival in HNSCC [10, $11,13]$. Consequently, strategies for neutralizing these cytoprotective factors involve shifting the cellular balance of anti- versus pro-apoptotic proteins in favor of the latter $[10,11,13]$.

In this respect, histone deacetylase inhibitors (HDACi), such as VPA, have emerged as promising chemotherapeutic agents by inducing a wide range of anti-tumoral activities, including induction of cell cycle arrest and apoptosis [14-20]. HDACi can correct aberrant genomic and non-genomic signaling by chromatin remodeling as well as histone/protein modifications [21]. Likewise, the ribonucleotide reductase inhibitor hydroxyurea (HU) sensitizes tumors to cancer therapyinduced apoptosis and has been used to treat HNSCC, particularly as part of chemoradiation platforms [22, 23]. However, it has not been investigated whether the combination of HDACi and HU may be applicable for the treatment of HNSCC nor have molecular mechanisms underlying its potential anti-tumoral activity been resolved.

Our study demonstrates for the first time that this drug combination efficiently eliminates HNSCC cancer cells by evoking expression of the pro-apoptotic protein BIM (B cell lymphoma 2 interacting mediator of cell death) and by downregulation of EGFR. This potent dual anti-tumoral activity suggests the clinical exploitation of this novel drug combination as a strategy to counteract therapy resistance in HNSCC.

\section{RESULTS}

\section{Combining VPA with HU cooperate in the killing of HNSCC tumor cells and loss of clonogenicity}

Cell lines representing HNSCC from different anatomical sites (Supplementary Table SI) were treated with VPA and HU alone and in combination. MTT assays revealed that although VPA and HU individually inhibited proliferation in a dose-dependent manner, coadministration of VPA/HU was most effective (Figure 1A and B; Supplementary Table SI). Similar results were obtained using a clonogenic cell survival assay (Figure 1C). FACS analysis showed that the VPA/HU combination potently induced apoptosis and confirmed that $\mathrm{HU}$ induced S-phase arrest (Figure 2A; Supplementary Figure S1A). Induction of cell death was already evident using a single dosage of VPA/HU $(0.5 \mathrm{mM} / 0.3 \mathrm{mM})$ and was not dependent on repetitive drug administration (Figure 2A). VPA/HU-induced apoptosis was further confirmed by independent experimental approaches. Immunoblot analysis showed enhanced cleavage of Caspases-3, -8 and -9 (Figure 2B; Supplementary Figure S1B). Also, increased Caspase-3 activity was detectable in lysates from treated cells, which could be counteracted by the pan-Caspase inhibitor Z-VAD-FMK (Figure 2B). The observed cleavage of Caspase-9, the loss of mitochondrial integrity, and DNA fragmentation upon treatment strongly imply that the intrinsic apoptosis pathway is responsible for VPA/HU induced cell death (Figure 2C; Supplementary Figure S1C). Similar results were obtained for several HNSCC cell lines tested and this effect was not restricted to VPA as treatment with other HU/HDACi combinations, such as TSA or butyrate, also resulted in cell death (Supplementary Table SI; Supplementary Figure S1D; data not shown). 
Induction of the pro-apoptotic protein BIM by VPA/HU treatment correlates with cell death

When analyzing the effects of VPA/HU treatment on the levels of pro- and anti-apoptotic BCL-2 proteins, we observed increased BIM levels (Figure 3A). Although

A
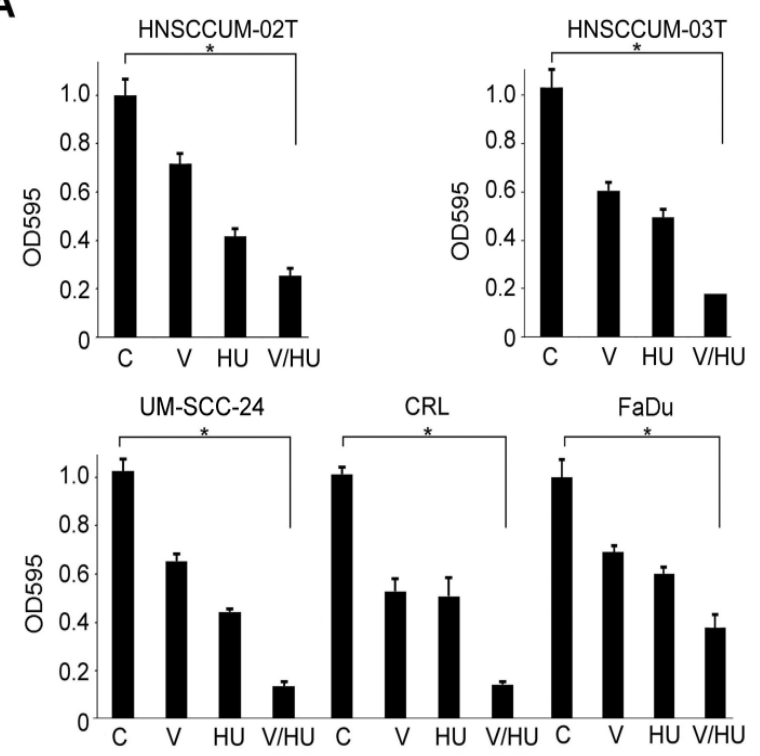

B
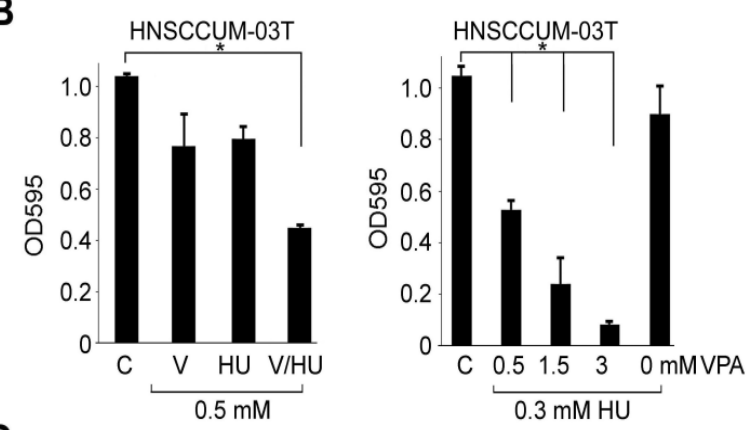

C
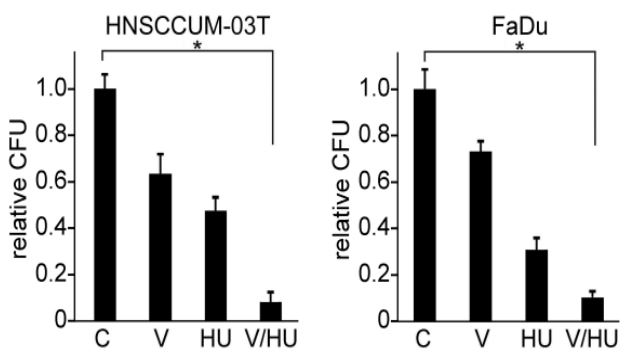

Figure 1: VPA and HU cooperate in HNSCC cells growth inhibition and loss of clonogenicity. Columns, mean; bars, \pm SD from three independent experiments. A) Indicated cell lines were treated with VPA (V), hydroxyurea (HU), VPA/HU (1.5 mM each) or PBS (C; set as 1$)$ for $48 \mathrm{~h}$, and proliferation was analyzed by the MTT assay. B) Treatment was performed with the indicated drug combinations or PBS (C; set as 1). Cell proliferation was assessed with MTT. C) VPA/ $\mathrm{HU}$ affects clonogenic cell survival. Cells were seeded and $24 \mathrm{~h}$ later treated with the indicated compounds or PBS. Surviving colonies were counted 10 days later and displayed as colony forming units (CFU) relative to the PBS control (C; set as 1) both drugs slightly induced expression of BIM, the effect was most prominent using the VPA/HU combination, correlating with enhanced apoptosis. The doses required to induce appreciable Caspase-3 activation and apoptosis were comparable to those necessary to induce BIM expression (Figure 2 and 3A). Notably, this effect was not restricted to VPA as treatment with other HU/HDACi combinations, such as with TSA or butyrate, also resulted in BIM induction and cell death (Supplementary Figure S1D; data not shown). Another BH-3-only protein, p53upregulated modulator of apoptosis (PUMA), was recently reported to mediate apoptosis induced by EGFR inhibitors in HNSCC cells [12]. In contrast to the strong induction of BIM by VPA/HU, immunoblot analysis revealed no enhanced expression of PUMA, BAX, and BCL-2/BCL$\mathrm{xL}$ (Figure $3 \mathrm{G}$ and data not shown). Moreover, VPA/HU could induce BIM in p53-negative PC3 cells, and BIM induction could be verified by independent methods in p53-mutant FaDu cells (Supplementary Figure S1E, S2A).

\section{BIM is critical for VPA/HU-induced tumor cell apoptosis}

To demonstrate that enhancing BIM levels triggers apoptosis in HNSCC cell lines, we first performed ectopic overexpression studies. Transfection of plasmids encoding a $\mathrm{BIM}_{\mathrm{EL}}-\mathrm{GFP}$ fusion or untagged $\mathrm{BIM}_{\mathrm{EL}}$, the longest BIM isoform (196 amino acids), resulted in efficient cell death (Figure 3B and not shown).

In order to further confirm the direct relevance of BIM for HDACi/HU-induced apoptosis, we used RNAi to deplete endogenous BIM. HNSCC cells with RNAimediated attenuated BIM expression displayed enhanced proliferation linked to reduced basal apoptosis rates (Figure 3C and data not shown). Furthermore, compared to the scrambled control, these cell lines showed significantly enhanced resistance to VPA/HU-induced cell death, as verified by analyzing Caspase-3 activation, TUNELstaining and loss of mitochondrial integrity (Figure 3D; Supplementary Figure S2B). Similar results were observed for TSA or butyrate (data not shown). Collectively, these results provide strong evidence that BIM is critical for the $\mathrm{HDACi} / \mathrm{HU}$-induced killing of cancer cells.

\section{VPA/HU enhances BIM expression p53- independently}

Increased BIM levels (Figure 3E) could be the result of transcriptional activation [11, 24]. Transfection of a BIM promoter-containing luciferase reporter revealed that VPA/HU indeed stimulated BIM transcription (Figure 3F). Of note, this was observed in cells bearing inactive p53 $(\mathrm{FaDu})$ as well as in p53-negative cells (PC3) (Supplementary Figure S1D and E). Experimental data collected with E2F- or c-JUN/FOS (AP1)-dependent 
reporter constructs transfected into HNSCC cells suggest a role of AP1 for the VPA/HU-mediated transcriptional activation of BIM (Supplementary Figure S2D). A BIM reporter containing an inactivated MYB-binding site was still responsive to treatment (Supplementary Figure S2C). Although the pharmacological inhibition of ERK signaling was critical for BIM expression in B-RAF/K-RAS mutant lung tumor cells [11], VPA/HU did not affect ERK levels but still evoked enhanced BIM expression in our cell models (Supplementary Figure S2E).

\section{BIM induction in tumor cells from head and neck carcinoma patients}

To underline the pathophysiological relevance of BIM not only for tumor cell models but also for the clinics, we first visualized BIM expression by IHC in tumor biopsies $(n=31)$. Using the immunoreactive score (IRS) [25], significantly elevated BIM levels $(p<0.001)$ were observed in cancer cells in the apoptotic tumor centers versus proliferating tumor margins (Figure 4A and 4B). Second, to definitely demonstrate that BIM is induced by
A

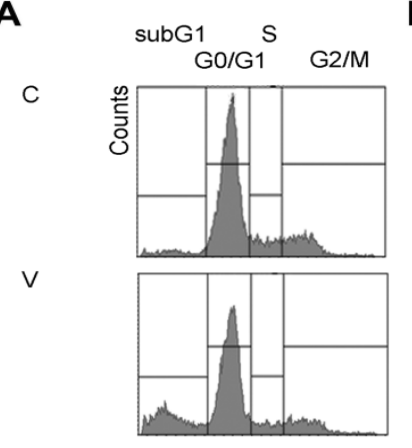

$\mathrm{HU}$

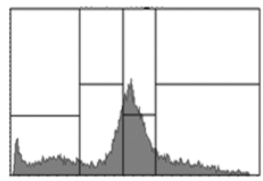

V/HU
$(1.5 \mathrm{mM})$

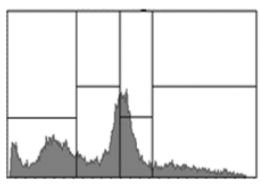

$(0.5 \mathrm{mM})$

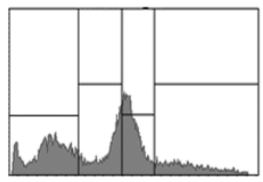

$\mathrm{V}$
$(1.5 \mathrm{mM}) /$

$\mathrm{HU}$

$(0.5 \mathrm{mM})$

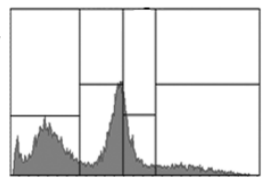

V/HU
$(2 \mathrm{X})$

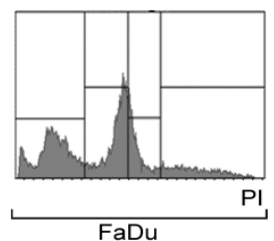

B

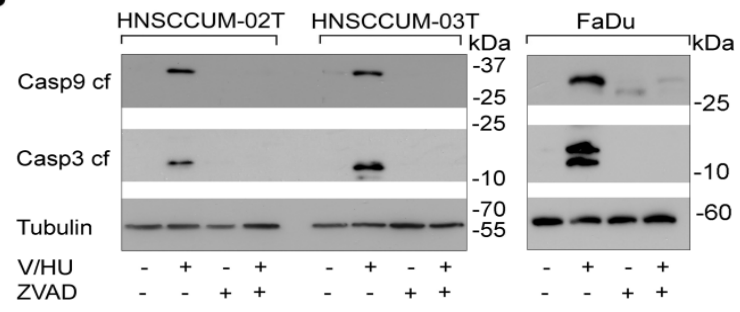

ZVAD

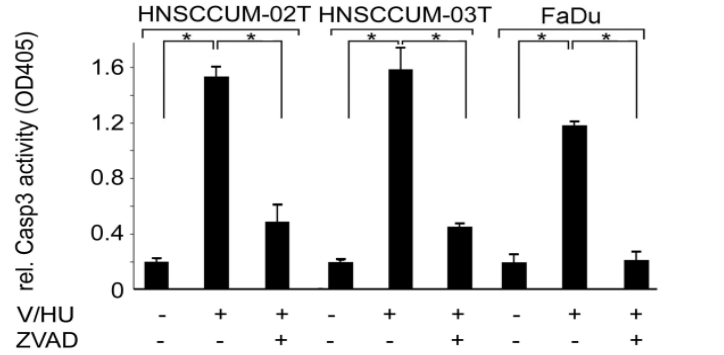

C
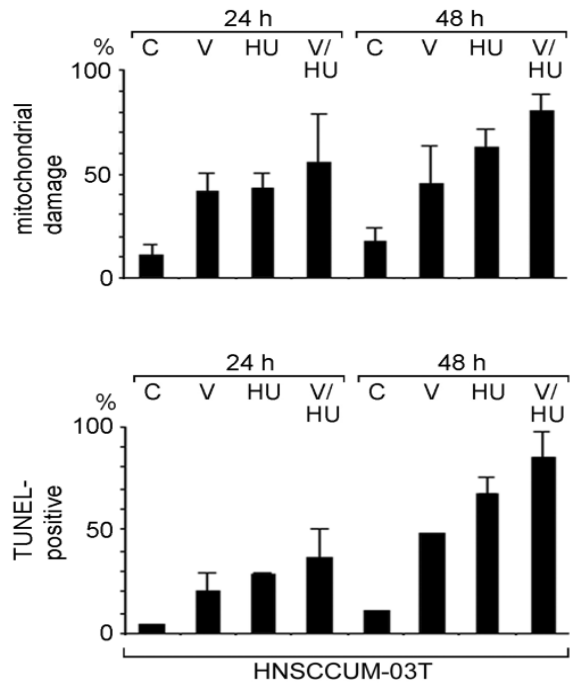

Figure 2: VPA and HU efficiently trigger apoptosis in HNSCC tumor cells. A) Drug-induced apoptosis was determined by measuring the sub-G1 population by flow cytometry (PI staining) $48 \mathrm{~h}$ post treatment. Induction of cell death was already evident using a single dose of VPA/HU $(1.5 \mathrm{mM} / 0.5 \mathrm{mM})$ and was not further enhanced by additional drug administration after $24 \mathrm{~h}$ (VPA/HU $2 \mathrm{X}$ ). B) $\mathrm{VPA} / \mathrm{HU}$ treatment $(1.5 \mathrm{mM}$ each; $48 \mathrm{~h}$ ) induced caspases activation sensitive to the pan-Caspase inhibitor Z-VAD. Immunoblot analysis demonstrated cleavage of Caspase-3 and -9 (upper panel; tubulin, loading control. Apoptosis was quantified by measuring Caspase-3 activity in cell lysates (lower panel). C) VPA/HU-induced cell damage shown by analyzing mitochondrial integrity and by TUNELstaining. The VPA/HU combination (1.5 mM each) caused significant mitochondrial damage already $24 \mathrm{~h}$ post treatment, resulting in loss of dimeric MitoCapture dye staining (upper panel). TUNEL-staining revealed VPA/HU-induced DNA-damage indicative of apoptotic cells (lower panel). 
VPA/HU also in primary tumor cells, we used cancer cells freshly isolated from HNSCC patients. Treatment of such tumor cells with VPA/HU resulted in enhanced BIM levels and cancer cell death (Figure 4C). Hence, regulated BIM expression appears to be relevant for disease progression and can be modulated by drug treatment.

\section{VPA/HU attenuates EGFR expression and signaling}

The EGFR is overexpressed in various epithelial malignancies and also represses BIM expression [11,
26]. As EGFR-targeting strategies are intensively tested in the clinics, we investigated the effects of VPA/HU treatment on this receptor. Interestingly, immunoblot analysis revealed that the combination of VPA/HU efficiently reduced the levels of total and phosphorylated EGFR (Figure 5A). To further examine the intracellular localization of EGFR, cells were treated with VPA/HU or PBS, and examined by IHC analysis. This analysis not only confirmed the reduction of overall EGFR levels, but also showed that such treatment affected the cell surface localization of the receptor and additionally enhanced BIM expression (Figure 5C). As a control, VPA/HU treatment appears not to cause an unspecific degeneration
A

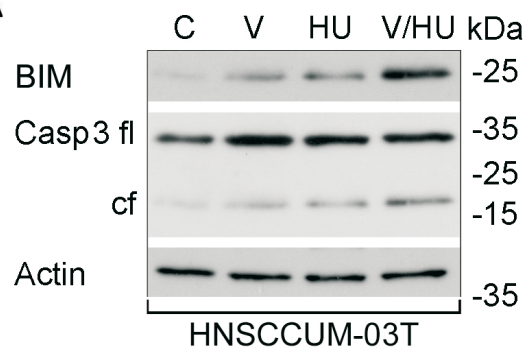

B

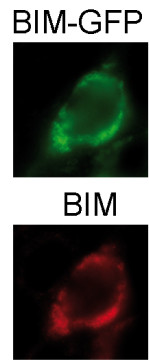

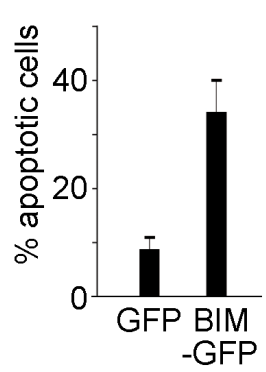

E
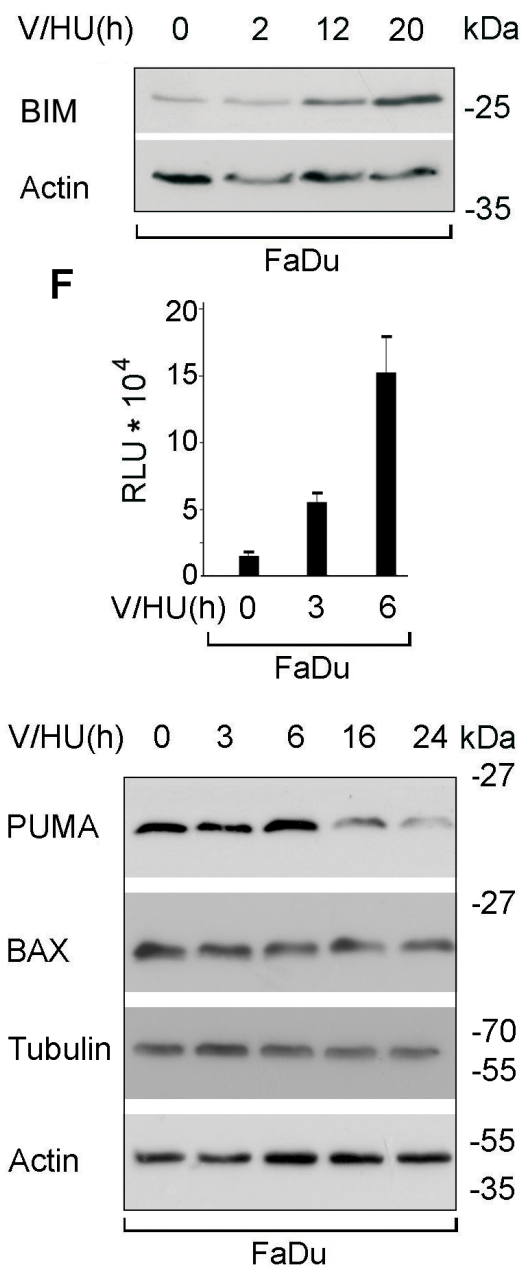

Figure 3: VPA/HU-treatment specifically induces the BCL-2 family protein BIM modulating cell proliferation and apoptosis. A) Cells were drug treated $(1.5 \mathrm{mM} ; 20 \mathrm{~h})$ and expression levels of the indicated proteins were visualized by immunoblot. Actin served to control equal loading of cell lysates. B) Cell death induction by ectopic expression of $\mathrm{BIM}_{\mathrm{EL}}-\mathrm{GFP} \mathrm{BIM}_{\mathrm{EL}}-\mathrm{GFP}_{\mathrm{Bas}}$ visualized $24 \mathrm{~h}$ post transfection in FaDu cells by direct and indirect immunofluorescence using $\alpha$-BIM Ab. C) Downregulation of BIM in HNSCCUM-03T cells stably transfected with BIM- (shBIM) versus scrambled-shRNA (shCtl) verified by immunoblot. Counting revealed that cells with attenuated endogenous BIM levels displayed enhanced proliferation. D) Decreased VPA/HU-induced apoptosis (1.5 mM each, 24 h) in BIM-depleted cells shown by immunoblot analyses for BIM and cleaved Caspase-3 (left), as well as by quantification of enzymatic Caspase-3 activity in cell lysates (right). E) Immunoblot revealed that VPA/HU (1.5 mM each) induced BIM in a time-dependent manner. F) VPA/HU-mediated transcriptional activation was monitored by analyzing luciferase activity. FaDu cells transfected with a BIM reporter were treated with VPA/HU (1.5 mM each). G) In contrast to the strong induction of BIM levels by VPA/HU, correlating with Caspase- 3 cleavage, no enhanced expression of PUMA and BAX was induced by VPA/HU. Actin and Tubulin served as loading controls. Columns, mean; bars, \pm SD from three independent experiments. 
of pro-survival proteins, as STAT3 levels, an important factor for head and neck carcinogenesis [27] or the growth factor receptor ERB-B2, were not significantly affected (Figure 5B; Supplementary Figure S2E). Collectively, these data provide evidence for a hitherto unknown molecular mechanism contributing to the potent anticancer activity of the VPA/HU combination. However, we cannot completely exclude the possibility that additional effects of VPA/HU on other proteins may at least partially contribute to the potent anti-tumoral activity of this drug combination.

\section{VPA/HU efficiently suppresses HNSCC tumor growth in murine xenotransplantation models}

Prior to testing the anti-tumoral activity of VPA/ $\mathrm{HU}$ in murine models, we first compared the cell killing activity of VPA/HU and of chemotherapeutic drugs currently used in the clinics. In our HNSCC cell culture models and at the concentrations used, VPA/HU treatment was more effective in triggering cell death, when compared to the EGFR inhibitors cetuximab and gefitinib or the DNA-damaging agent cisplatin (Supplementary Figure S2F). Notably, interference with EGFR signaling by gefitinib also induced BIM expression (Supplementary Figure S2G).
These in vitro-results encouraged us to examine whether VPA/HU treatment also inhibits tumor growth in vivo. Using a xenograft model, established FaDu tumors were treated with VPA/HU $(350 \mathrm{mg} / \mathrm{kg}, 750 \mathrm{mg} / \mathrm{kg}$ body weight) or PBS control i.p. for 14 days. Administration of VPA/HU to FaDu tumor-bearing mice significantly inhibited tumor growth $(\mathrm{p}<0.001)$ (Figure 5D). To visualize whether drug treatment also enhanced BIM levels and caused EGFR attenuation in vivo, tumors from treated and control animals were analyzed by IHC. Enhanced BIM levels and reduced EGFR expression were observed in tumors from VPA/HU treated animals compared to those from control mice (Figure 5E). The above data not only confirmed the potent anti-cancer activity of the VPA/HU combination in vivo, but also demonstrated the in vivo-relevance of the molecular mechanisms identified in our cell culture models. Of note, drug treatment of non-transplanted nude mice did not result in loss of body weight, and no organ damage was evident by histological inspection of treated C57BL/6 mice (data not shown). Hence, the anti-tumoral effect of our drug combination was not mediated by unspecific cytotoxicity.
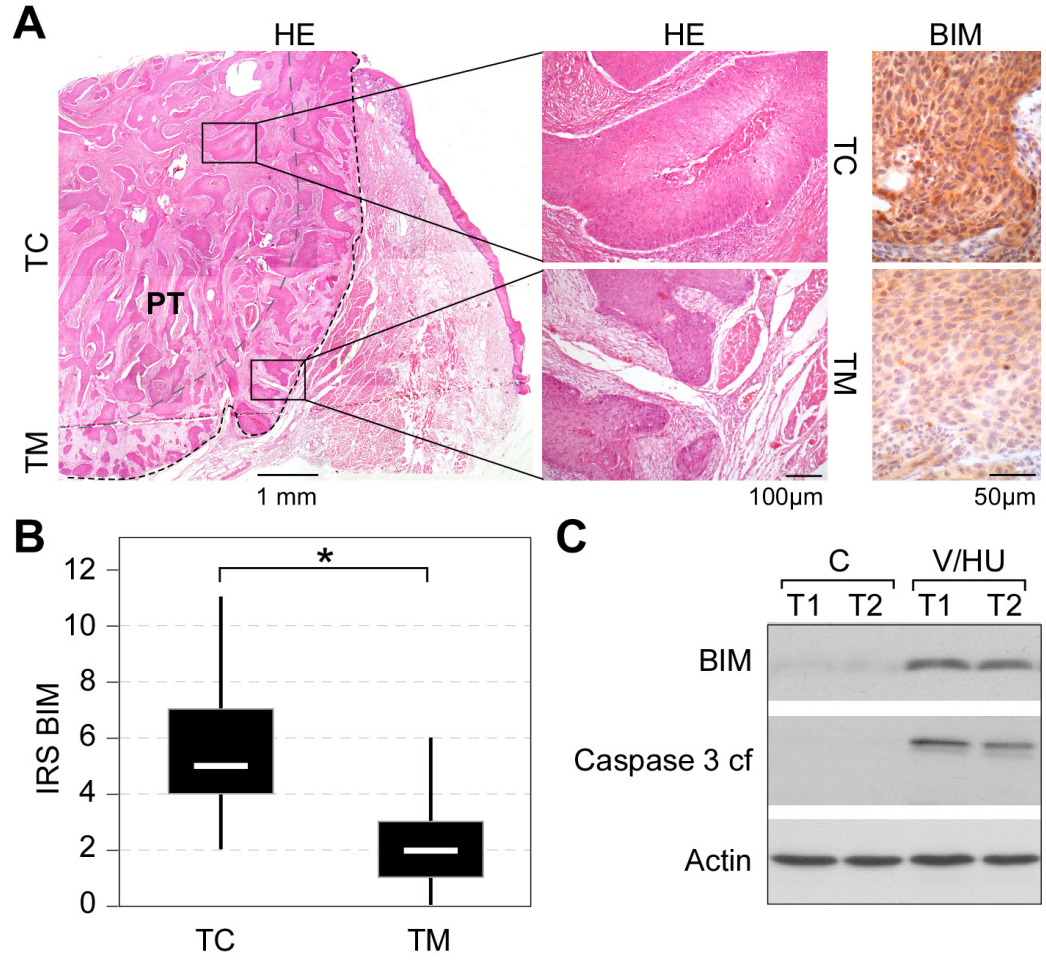

Figure 4: BIM expression in tumor biopsies from head and neck carcinoma patients. A) Detection of BIM in HNSCC tumor centers (TC) versus proliferating tumor margins (TM). Representative example of an oral SCC (G2, pT3, pN0) stained with hematoxylin/ eosin (HE) (left panel) and immunohistochemical visualization of BIM using $\alpha$-BIM Ab (right panel). B) Box plot (with range) for BIM IRS reveals enhanced BIM expression in the TC in HNSCC patient biopsies $\left({ }^{*} \mathrm{p}<0.001 ; \mathrm{n}=31\right)$. C) Treatment of freshly isolated tumor cells from two patients (T1: Hypopharynx, G2, pT3, pN0; T2: oral cavity, G3, pT3, pN0) with VPA/HU (1.5/0.5 mM) for 48 h resulted in BIM induction and Caspase- 3 activation. Indicated proteins were detected by immunoblot analysis. Actin served as loading control 


\section{DISCUSSION}

Rational combination therapies are considered as the most efficient strategy to combat cancer $[9,28]$. As the success of these treatments requires a profound molecular knowledge of their underlying mechanisms [29-31], we here studied the combination of two drugs, which have been suggested to affect tumor cell death by different mechanisms [23, 32, 33]. Employing comprehensive cell culture and in vivo models we here demonstrate for the first time that combining HDACi with HU potently kills HNSCC by a dual mechanism. Although such agents have been shown to individually affect tumor cells [22, 32], the (pre)clinical anti-tumor activities of the HDACi/ $\mathrm{HU}$ combinations as well as the underlying molecular mechanisms have not been resolved so far for HNSCC.

Treatment of malignant cells with HDACi can induce a wide range of anticancer effects including

A

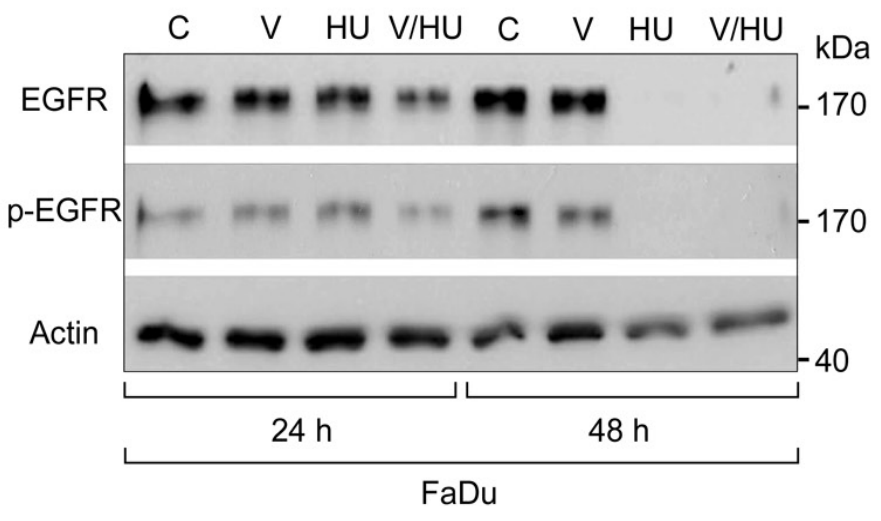

apoptosis, cell cycle arrest and differentiation $[15,18$, $20,34,35]$. Numerous HDACi have been tested in the clinics or are currently the subject of ongoing early-phase clinical trials, including HNSCC [14, 19, 36-38]. Since HDACi monotherapies seem not to be effective against solid tumors, their full therapeutic potential will be best realized through combination with other anticancer agents $[17,19,34]$. However, most reports do not provide a welldefined molecular rationale for combining an HDACi with a given agent. Moreover, the molecular events underlying cooperative combination effects are often still to be identified [17, 19, 34].

In contrast, we here provide convincing evidence that activation of the proapoptotic BH3-only protein BIM together with EGFR attenuation are key regulators for VPA/HU-induced tumor cell death. This conclusion is based on several lines of evidence: First, HDACi/HU induced BIM upregulation, induction of apoptosis and
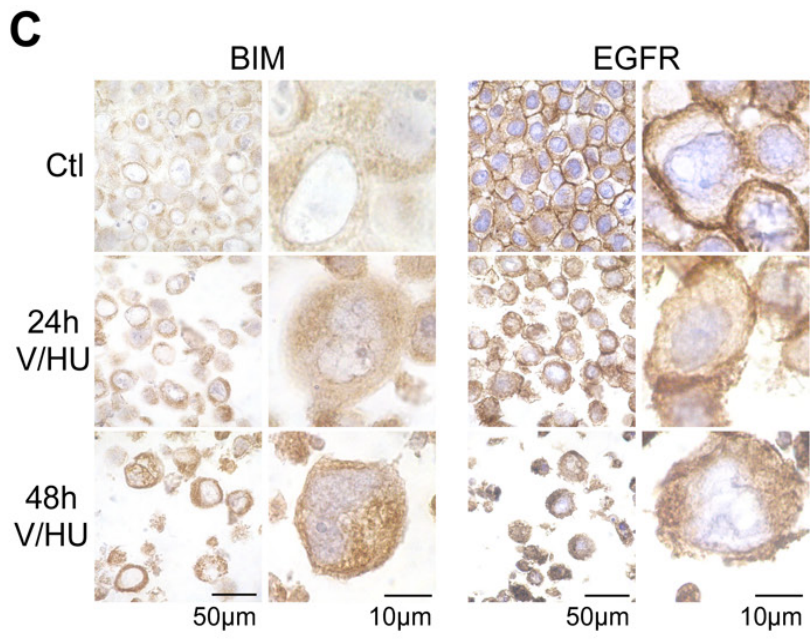

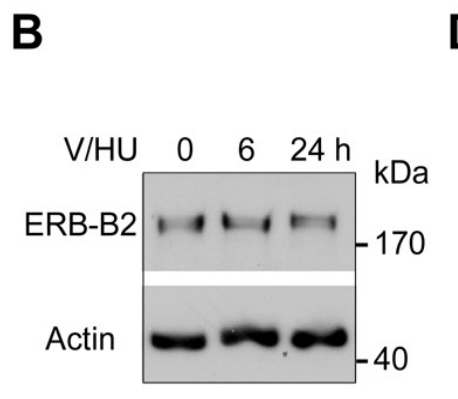

D
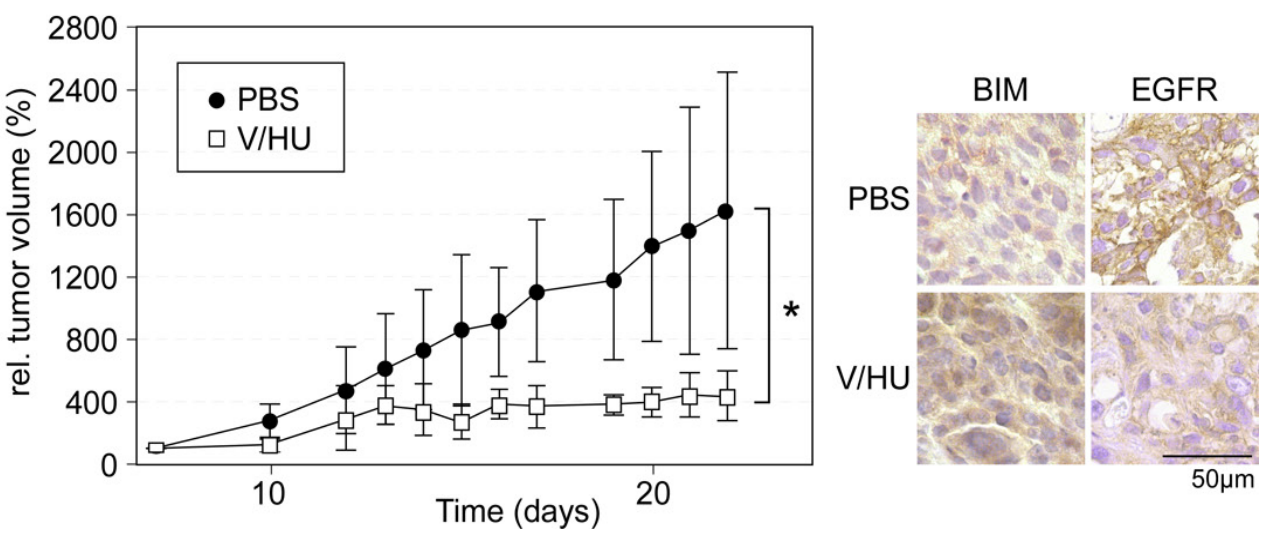

Figure 5: Effects of VPA/HU on the growth factor receptors EGFR and ERB-B2, and suppression of HNSCC tumor growth in vivo. A/B) FaDu cells were treated with V, HU, VPA/HU (1.5 mM each) or PBS (C). Expression of the indicated proteins was analyzed by immunoblotting. Actin served to control equal loading. VPA/HU treatment effectively reduced the levels of total and phosphorylated EGFR, whereas ERB-B2 levels were not affected. C) FaDu cells treated with VPA/HU (1.5 mM each) were FFPE and used for IHC analysis employing EGFR- or BIM-specific Ab. Treatment resulted in reduced expression and cell surface localization of the EGFR as well as increased BIM levels. D) VPA/HU suppressed the growth of FaDu HNSCC xenograft tumors. Growth curve of tumors subjected to VPA/HU (i.p., $350 \mathrm{mg} / \mathrm{kg}$ and $750 \mathrm{mg} / \mathrm{kg}$ body weight) or PBS control. Nude mice were inoculated with FaDu tumor cells. When tumors had reached the target size of $0.1 \mathrm{~cm}^{3}$, mice were treated once every second day for 14 days. ${ }^{*} \mathrm{p}<0.001, n=4$ animals per treatment group, data are mean \pm SD. E) Enhanced BIM and reduced EGFR levels in xenograft tumors at the end of VPA/HU treatment. BIM and EGFR expression was visualized by IHC. 
loss of the clonogenic potential of HNSCC cell lines derived from different anatomical sites. This finding will be clinically relevant as SCC from different anatomical regions, like the hypopharynx or the oral cavity, differ in their clinical prognosis and response [6], but do express BIM as shown by the analysis of tumor biopsies. Currently, the clinical relevance of results obtained in permanent tumor cell lines are questioned, as such cell lines may differ from primary tumor cells at their molecular level [39]. However, also freshly isolated tumor cells but not fibroblasts from HNSCC patients responded to $\mathrm{VPA} / \mathrm{HU}$ administered at therapeutically achievable levels (0.5-1.5 $\mathrm{mM})$ with BIM induction, EGFR downregulation and apoptosis. Several clinical studies have already demonstrated that VPA or HU plasma levels in the $0.5-1.5 \mathrm{mM}$ range can be achieved in cancer patients without major toxicity [37, 40, 41], supporting an expectable clinical efficacy of the VPA/HU combination. Second, ectopic expression and RNAi experiments convincingly demonstrate that BIM is the BCL-2 family member essential for VPA/HU-induced cancer cell death. Third, VPA/HU efficiently prevented progression of HNSCC tumors in nude mice correlating with enhanced BIM levels and attenuation of EGFR surface expression. The tumor growth delay achieved with the combination treatment was highly significant compared with the untreated control, without major toxicity.

BIM-evoked apoptosis was found crucial for epithelial tumor cell death triggered by anti-cancer therapeutics $[11,42,43]$. We found that especially the VPA/HU combination cooperatively activated BIM at the transcriptional level. To date, several transcription factors, including p53, E2F, c-JUN/FOS (AP1), MYB, RUNX3, and FOXO3A have been reported to regulate $B I M$ transcription $[11,24,44]$. Our data suggest that transcriptional activation of $B I M$ in HNSCC by VPA/HU is mediated via AP1, which is not subject to mutation in oral cancer patients [45]. It is possible that HU-mediated S-phase-dependent induction of c-JUN enhances BIM expression [46]. Also, the activity of c-JUN is repressed by the HDAC3-NCoR complex [47], which is particularly sensitive to inhibition by VPA [15]. Phosphorylation of c-JUN by JUN kinase (JNK) permits dissociation of HDAC3 and c-JUN-dependent transcription [47]. HU has been shown to activate JNK in vivo [48], which may contribute to c-JUN-dependent BIM induction.

Although the BH-3-only protein PUMA was recently reported to mediate apoptosis of HNSCC cell lines induced by EGFR tyrosine kinase inhibitors [12], VPA/HU-mediated PCD did not require induction of the p53 targets PUMA and BAX. This finding seems to be of clinical relevance as VPA/HU-induced cell death does not rely on p53, which is mutated in the majority of HNSCC [49]. Moreover, HNSCC cells with attenuated BIM expression displayed enhanced proliferation. Our finding that lowering this endogenous pro-apoptotic factors not only increases tumor cell survival but also proliferation might be involved in HNSCC therapy response and disease progression. Although BIM plays a major role in death signaling, this does not rule out the additional participation of other BCL-2 family members and/or other apoptosis inhibitor proteins $[12,50]$.

As we did not observe increased BCL-2/BCL-xL levels upon VPA/HU treatment potentially neutralizing increased BIM expression, it is conceivable to speculate that the addition of BH3 mimetics, such as ABT-737, may not further boost tumor cell death. Killing of $B-R A F$ mutant lung tumor cells with ABT-737 required BIM induction by inhibition of ERK signaling. Furthermore, $B-R A F$ wild type cancer cells were even largely resistant to this treatment [51]. As the frequency of $R A F / R A S$ mutations in HNSCC is rather low $[52,53], \mathrm{VPA} / \mathrm{HU}$ is hence likely to be clinically more effective when compared to certain other attempts to alter BCL-2 family members [11]. It will furthermore be interesting to analyze the putative impact of VPA/HU on other molecules important for HNSCC survival. These are for example Aurora kinase-A, which shares signaling pathways with EGFR [54], and the structural protein NSP 5a3a promoting HNSCC apoptosis via the p53-related factor p73 [29, 30].

HNSCC tumors are often characterized by deregulated EGFR signaling due to receptor overexpression, activating receptor mutations and aberrant downstream signaling cascades [7]. Survival is secured by the activation of MEK and ERK kinases, leading to stabilization of MCL-1, activation of BCL-2, and degradation of BIM [11]. (Pre)clinical approaches interfering with EGFR signaling trigger apoptosis by also enhancing BIM expression [7, 11; this study]. Importantly, we show that VPA/HU treatment efficiently reduced not only EGFR levels and signaling, but also attenuated EGFR cell surface localization in cell and xenograft models. Although recent antibody-based EGFR targeting strategies have gained major attention, the clinical response rates to such therapies are rather low. In addition, the mechanism(s) conferring resistance of HNSCC against agents targeting the EGFR are ill-defined [8, 9], and the required agents are expensive and often show a suboptimal pharmacodynamic profile. VPA and HU are stable lowercost drugs, which can be administered orally [14, 22, 33]. Moreover, the VPA/HU combination may represent a contingency treatment option for patients acquiring resistance to other EGFR-targeting approaches [8, 23, 54, 55]. Both, HU and VPA target major and general cellular survival factors that are misregulated in a variety of human cancers. E.g., cell cycle control is lost in the vast majority of malignancies, and HDACs are frequently overexpressed during tumorigenesis [17]. The molecular mechanisms underlying EGFR attenuation upon exposure of malignant cells to VPA/HU in vitro and in mice remain to be resolved in detail. These may involve HU-induced replication arrest, known to affect oncogenic tyrosine kinase signaling 
[56], and/or the E3 ubiquitin ligase c-CBL, which controls EGFR ubiquitination and lysosomal degradation [57].

A major advantage allowing to expedite potential clinical studies employing VPA/HU for the treatment of HNSCC is the fact that both agents are FDA approved drugs. Albeit hardly in combination, both are used frequently in the clinic $[17,22,37]$. Thus, one can rely on an extensive knowledge on the therapeutically most effective dose and pharmacodynamics of these agents [32, 38]. Also, dose-limiting but clinically manageable side effects are known, including myelosuppression, fatigue, nausea, and diarrhea $[22,32,33,37,38]$. In contrast, neither toxicity profiles nor clinical efficacy are known for other anti-tumor strategies targeting BCL-2 family members [51].

Our study has several potential limitations. One is the use of immunocompromised mice as preclinical models of human malignancies, which do not always reflect the heterogeneity and complexity seen in patients. Second, although significantly higher concentrations of VPA or HU were previously used in tumor models without major signs of toxicity [58-60], the VPA/HU doses employed in the xenograft model exceed VPA/HU concentrations currently used in patients $[22,40]$. However, cell culture results suggest that even low VPA/HU concentrations will show anti-tumoral efficacy in vivo. The minimal effective dose, the optimal application route (oral, i.p., i.v.), as well as the effects of long-term treatment needs to be determined in comprehensive preclinical studies prior to prospective clinical trials.

In conclusion, in addition to current chemoradiotherapy platforms combining HU with HDACi might prove as an extra treatment option for HNSCC. Although not examined in this study, such drug combinations may be of therapeutic interest also for other tumor entities characterized by therapy resistance and EGFR overexpression, such as colon cancer.

\section{METHODS}

\section{Ethics Statement}

Investigation has been conducted in accordance with the ethical standards and according to the Declaration of Helsinki and according to national and international guidelines and has been approved by the authors' institutional review board.

\section{Cells, transfections and luciferase assay}

Cultivation of the indicated head and neck cancer and other tumor cell lines has been described in detail [ 25 , 61-64] (Supplementary Table SI). Cell lines constitutively expressing shRNA directed against BIM or a scrambled control were generated by transfection of pHR-THTBIMshRNA-SFFV-eGFP or pHR-THT-scr_shRNA-SFFVeGFP [65], respectively. Cells were transfected using PEI (Sigma Aldrich, Munich, Germany) or Lipofectamine (Invitrogen, Karlsruhe, Germany) and selected by addition of puromycin ( $1 \mu \mathrm{g} / \mathrm{ml}$; Sigma Aldrich, Munich, Germany). Luciferase reporter assays were carried out in triplicate and repeated thrice as stated [62].

\section{Microscopy and image analysis}

Observation, image analysis and quantification of protein localization were performed as described [66]. DNA/cell nuclei were visualized by Hoechst 33258 staining (Sigma Aldrich, Munich, Germany) as described before [66]. At least 100 fluorescent cells were analyzed in three independent experiments.

\section{Patients, tissue sampling and primary cell isolation}

Biopsies of patients diagnosed with HNSCC and treated at the Departments of Oral and Maxillofacial Surgery and ENT of the University Hospitals in Frankfurt and Mainz were analyzed. Tumor specimens were collected from primary tumors of patients who underwent surgery. All cases were clinically and histologically diagnosed according to established criteria including grading and TNM-classification (Supplementary Table SII). Studies of human tissue biopsies were performed according to the requirements of the local ethics committee (\#83756604), and informed consent has been obtained in accordance with the Declaration of Helsinki. For the isolation of primary cancer cells, tumor specimens were cut into small pieces and enzymatically digested with collagenase typeI/hyaluronidase (Sigma Aldrich, Munich, Germany) in RPMI-1640 (Invitrogen, Karlsruhe, Germany) at $37^{\circ} \mathrm{C}$ overnight. Following digestion, dissociated cells were passed through a cell strainer, and epithelial cancer cells and fibroblast were isolated by MACS ${ }^{\circledR}$ separation using CD326 (EpCAM) or $\alpha$-fibroblast MicroBeads (Miltenyi Biotec GmbH, Bergisch Gladbach, Germany) according to the manufacturer's recommendations. Cells were propagated for one week as described [67] and subjected to analysis.

\section{Drug treatment and clonogenic survival assay}

Cells were treated with VPA, trichostatin A (T), sodium butyrate (B), HU, or cisplatin (Sigma Aldrich, Munich, Germany) as described [16, 67]. The EGFR antagonists gefitinib (Tocris Bioscience, Ellisville, USA) and cetuximab (ImClone, New York, NY, USA) were applied for $48 \mathrm{~h}$. For colony formation assays, $1 \times 10^{3}$ cells/ 
T25 flask were seeded in triplicate. $24 \mathrm{~h}$ later, cells were treated with the indicated compounds or PBS control and further cultivated for 10 days. Drug-containing medium was replaced every day. Cells were fixed and stained with Giemsa. Colonies containing $>50$ cells were counted automatically using a colony counter (Oxford Optronics, Oxford, United Kingdom). Data shown are calculated from the mean values of three independent experiments.

\section{Antibodies (Ab)}

Ab were: $\alpha$-PUMA (4976) (NEB Cell Signaling, Frankfurt, Germany); $\alpha$-Survivin (Novus NB 500-201; Novus Biologicals, Littleton, CO); anti-ß-Actin (A2066), a-BIM (B7929), anti-alpha-Tubulin (T5168) (Sigma Aldrich, Munich, Germany); $\alpha$-BCL-XL (66461A), $\alpha$-Caspase-8 (9745), -9 (9501) (Pharmingen); cleaved Caspase-3 (9664) (Cell Signaling); $\alpha$-BAX (sc-20067), $\alpha$-Caspase-3 (sc-7272/-7148), $\alpha$-ERB-B2 (sc-284), $\alpha$-EGFR (sc-81449), $\alpha$-ERK1/2 (sc-135900), $\alpha$-STAT3 (sc482) (Santa Cruz Biotechnology, Heidelberg, Germany). Appropriate HRP-, Cy3- or FITC-conjugated secondary antibodies (Sigma Aldrich, Munich, Germany; Santa Cruz Biotechnology, Heidelberg, Germany) were used.

\section{Protein extraction, immunoblot analysis and immunofluorescence}

Preparation of whole lysates from cells or tissue, coimmunoprecipitations and immunoblotting were carried out as described $[61,62]$. Equal loading of lysates was controlled by reprobing blots for Actin or Tubulin as described [62]. Immunofluorescence was performed as described in detail $[62,66,68]$.

\section{Immunohistochemistry (IHC)}

Tissue samples or transfected cell pellets were formalin fixed, paraffin embedded (FFPE) and processed for IHC as described [25, 61]. For antigen retrieval, sections were treated in a pressure cooker with Tris buffer (10 mM, pH9.0) for BIM or were treated with proteinase K (S3020, DakoCytomation, Glostrup, Denmark) for $8 \mathrm{~min}$ at room temperature for EGFR detection. Sections were incubated with primary Ab $(\alpha$-BIM, 1:800; $\alpha$-EGFR 1:50) overnight at $4^{\circ} \mathrm{C}$. For visualization, the EnVision $^{\circledR}$ detection system (Dako GmbH, Hamburg, Germany) was applied as described [25]. Sections were counterstained with hematoxylin. Negative control slides without primary $\mathrm{Ab}$ were included for each staining. For quantification, sections were scanned at low power to identify areas of positivity and three random fields were selected. Expression levels for BIM were scored semiquantitatively based on staining intensity and distribution using the immunoreactive score (IRS) [25]. IRS=SI (staining intensity) x PP (percentage of positive cells). SI is assigned as 0 , negative; 1 , weak; 2 , moderate; 3 , strong. $\mathrm{PP}$ is defined as 0 , negative; $1,<5 \% ; 2,6-30 \% ; 3,31-$ $60 \%$; and $4,>60 \%$ positive cells.

\section{Measurement of apoptosis, cell cycle and viability}

Assessment of apoptosis was performed by quantifying Caspase-3-dependent hydrolysis of a fluorogenic substrate and by immunoblot-based detection of cleaved caspases [62]. Apoptotic cells were visualized by analyzing mitochondrial integrity using the PromoKine Mitochondrial Apoptosis Staining Kit (PromoCell; Heidelberg, Germany), staining of fragmented nuclei with Hoechst dye or TUNEL-staining as described [69]. Briefly, 200 cells from three separate images were inspected and the percentage of apoptotic cells determined. Cell viability was calculated employing MTT-assays and the electric sensing zone method as described in detail [61, 62]. Cell cycle profiles were obtained by FACS-mediated analysis of prodidium iodide (PI) stained cells as outlined before [16].

\section{Animals and xenograft tumors}

All animal work has been conducted according to relevant national and international guidelines. For animal studies, FaDu cells $\left(2 \times 10^{6}\right)$ cells were implanted into both flanks of four-week-old female NMRI nu/nu mice (Harlan Winkelmann, Hamburg, Germany) [69], and were allowed to establish for 7 days followed by treatment for 14 days. VPA/HU (350 mg/kg, $750 \mathrm{mg} / \mathrm{kg}$ body weight) or PBS control was administered intraperitoneally (i.p.) every second day as described [58]. Mice were randomized into groups (4 mice/group) such that the average tumor volumes across the groups were equal. Tumor growth was monitored using calipers to calculate tumor volumes according to the formula: length $\mathrm{x} \pi$ width $^{2} \mathrm{x} 0.52$. Animals were euthanized at the end of the study, and the tumors processed for IHC analysis as described [69]. To assess drug-induced side effects, VPA/HU or PBS treatment was also performed in non-transplanted NMRI $n u / n u$ or eight-week-old female C57BL/6 mice (2 mice/ group). All animal experiments were approved by the Institutional Animal Care and Use Committee at the University of Mainz.

\section{Statistical analysis}

For all experiments stating $p$-values, a paired Student's t-test was performed. Unless stated otherwise, $p$-values represent data obtained from three independent experiments done in triplicate. $p$-values $<0.05$ were 
considered as significant.

\section{Plasmids and RNAi}

The expression construct for human $\mathrm{BIM}_{\mathrm{EL}}$, pCDNA4/TO-BIM ${ }_{\mathrm{EL}}$, was described [70]. For expression of a BIM $_{E L}-$ GFP fusion, BIM ${ }_{E L}$ cDNA was PCR amplified and cloned into pc3-GFP (pc3BIM $\mathrm{EL}_{-\mathrm{GFP}}$ ) as stated before [66]. pGL3-luciferase reporter constructs containing the BIM promoter, MYB, E2F or AP1 binding sites were introduced previously [24]. Lentiviral vectors constitutively expressing shRNA directed against BIM or a scrambled control, pHR-THT-BIMshRNA-SFFV-eGFP or pHR-THT-scr_shRNA-SFFV-eGFP, respectively, were reported [65].

\section{ACKNOWLEDGEMENTS}

We thank T. Heinzel for invaluable discussions and support, S. Friedel and G. Greiner for excellent technical assistance, I. Behrmann for providing PC3 cells, S.C. Biswas for luciferase-reporter constructs, C. Ploner and G. Häcker for BIM plasmids. Grant support: German Cancer Aid (FKZ102362); Landesprogramm ProExzellenz (PE123-2-1); Head and Neck Cancer Foundation; Novartis-Foundation for Therapeutic Research; WilhelmSander Foundation (Nr. 2010.078.1); Stiftung RheinlandPfalz für Innovation; DFG KN973/1-1.

\section{REFERENCES}

1. Lippert BM, Knauer SK, Fetz V, Mann W, Stauber RH. Dynamic survivin in head and neck cancer: molecular mechanism and therapeutic potential. Int J Cancer. 2007; 121: 1169-74.

2. Jemal A, Siegel R, Ward E, Hao Y, Xu J, Thun MJ. Cancer statistics, 2009. CA Cancer J Clin. 2009; 59: 225-49.

3. Forastiere AA, Ang KK, Brizel D, Brockstein BE, Burtness BA, Cmelak AJ, Colevas AD, Dunphy F, Eisele DW, Goepfert H, Hicks WL, Jr., Kies MS, Lydiatt WM, Maghami E, Martins R, McCaffrey T, Mittal BB, Pfister DG, Pinto HA, Posner MR, Ridge JA, Samant S, Schuller DE, Shah JP, Spencer S, Trotti A, 3rd, Weber RS, Wolf GT, Worden F. Head and neck cancers. J Natl Compr Canc Netw. 2008; 6: 646-95.

4. Fakhry C, Westra WH, Li S, Cmelak A, Ridge JA, Pinto $\mathrm{H}$, Forastiere A, Gillison ML. Improved survival of patients with human papillomavirus-positive head and neck squamous cell carcinoma in a prospective clinical trial. J Natl Cancer Inst. 2008; 100: 261-9.

5. Forastiere AA. Chemotherapy in the treatment of locally advanced head and neck cancer. J Surg Oncol. 2008; 97: 701-7.

6. Argiris A, Karamouzis MV, Raben D, Ferris RL. Head and neck cancer. Lancet. 2008; 371: 1695-709.

7. Bonner JA, Harari PM, Giralt J, Azarnia N, Shin DM, Cohen RB, Jones CU, Sur R, Raben D, Jassem J, Ove R, Kies MS, Baselga J, Youssoufian H, Amellal N, Rowinsky EK, Ang KK. Radiotherapy plus cetuximab for squamouscell carcinoma of the head and neck. N Engl J Med. 2006; 354: $567-78$.

8. Morris LG, Chan TA. Resistance to EGFR inhibitors: Molecular determinants and the enigma of head and neck cancer. Oncotarget. 2011; 2: 894-5.

9. Blagosklonny MV. How cancer could be cured by 2015 . Cell Cycle. 2005; 4: 269-78.

10. Youle RJ, Strasser A. The BCL-2 protein family: opposing activities that mediate cell death. Nat Rev Mol Cell Biol. 2008; 9: 47-59.

11. Hendrickson AW, Meng XW, Kaufmann SH. Anticancer therapy: boosting the bang of Bim. J Clin Invest. 2008; 118: 3582-4.

12. Sun Q, Ming L, Thomas SM, Wang Y, Chen ZG, Ferris RL, Grandis JR, Zhang L, Yu J. PUMA mediates EGFR tyrosine kinase inhibitor-induced apoptosis in head and neck cancer cells. Oncogene. 2009.

13. Stauber RH, Mann W, Knauer SK. Nuclear and cytoplasmic survivin: molecular mechanism, prognostic, and therapeutic potential. Cancer Res. 2007; 67: 5999-6002.

14. Bots M, Johnstone RW. Rational combinations using HDAC inhibitors. Clin Cancer Res. 2009; 15: 3970-7.

15. Buchwald $\mathrm{M}$, Krämer $\mathrm{OH}$, Heinzel T. HDACi--targets beyond chromatin. Cancer Lett. 2009; 280: 160-7.

16. Krämer $\mathrm{OH}$, Knauer SK, Zimmermann D, Stauber $\mathrm{RH}$, Heinzel T. Histone deacetylase inhibitors and hydroxyurea modulate the cell cycle and cooperatively induce apoptosis. Oncogene. 2008; 27: 732-40.

17. Müller S, Krämer OH. Inhibitors of HDACs--effective drugs against cancer? Curr Cancer Drug Targets. 2010; 10: 210-28.

18. Sikandar S, Dizon D, Shen X, Li Z, Besterman J, Lipkin SM. The class I HDAC inhibitor MGCD0103 induces cell cycle arrest and apoptosis in colon cancer initiating cells by upregulating Dickkopf-1 and non-canonical Wnt signaling. Oncotarget. 2010; 1: 596-605.

19. Krämer $\mathrm{OH}, \mathrm{Göttlicher} \mathrm{M,} \mathrm{Heinzel} \mathrm{T.} \mathrm{Histone} \mathrm{deacetylase}$ as a therapeutic target. Trends in Endocrinology and Metabolism. 2001; 12: 294-300.

20. Krämer $\mathrm{OH}$, Zhu $\mathrm{P}$, Ostendorff HP, Golebiewski M, Tiefenbach J, Peters MA, Brill B, Groner B, Bach I, Heinzel T, Göttlicher M. The histone deacetylase inhibitor valproic acid selectively induces proteasomal degradation of HDAC2. Embo J. 2003; 22: 3411-20.

21. Spange S, Wagner T, Heinzel T, Krämer OH. Acetylation of non-histone proteins modulates cellular signalling at multiple levels. Int J Biochem Cell Biol. 2009; 41: 185-98.

22. Seiwert TY, Haraf DJ, Cohen EE, Stenson K, Witt ME, Dekker A, Kocherginsky M, Weichselbaum RR, Chen 
HX, Vokes EE. Phase I study of bevacizumab added to fluorouracil- and hydroxyurea-based concomitant chemoradiotherapy for poor-prognosis head and neck cancer. J Clin Oncol. 2008; 26: 1732-41.

23. Seiwert TY, Salama JK, Vokes EE. The chemoradiation paradigm in head and neck cancer. Nat Clin Pract Oncol. 2007; 4: 156-71.

24. Biswas SC, Shi Y, Sproul A, Greene LA. Pro-apoptotic Bim induction in response to nerve growth factor deprivation requires simultaneous activation of three different death signaling pathways. J Biol Chem. 2007; 282: 29368-74.

25. Engels K, Knauer SK, Metzler D, Simf C, Struschka O, Bier C, Mann W, Kovacs AF, Stauber RH. Dynamic intracellular survivin in oral squamous cell carcinoma: underlying molecular mechanism and potential as an early prognostic marker. J Pathol. 2007; 211: 532-40.

26. Deng J, Shimamura T, Perera S, Carlson NE, Cai D, Shapiro GI, Wong KK, Letai A. Proapoptotic BH3-only BCL-2 family protein BIM connects death signaling from epidermal growth factor receptor inhibition to the mitochondrion. Cancer Res. 2007; 67: 11867-75.

27. Leeman RJ, Lui VW, Grandis JR. STAT3 as a therapeutic target in head and neck cancer. Expert Opin Biol Ther. 2006; 6: 231-41.

28. Schnaiter A, Stilgenbauer S. Refractory chronic lymphocytic leukemia--new therapeutic strategies. Oncotarget. 2010; 1: 472-82.

29. D'Agostino L, Giordano A. NSP 5a3a: a potential novel cancer target in head and neck carcinoma. Oncotarget. 2010; 1: 423-35.

30. D'Agostino L, Giordano A. A Novel Dual Signaling Axis for NSP 5a3a induced apoptosis in Head and Neck Carcinoma. Oncotarget. 2011; 2: 1055-1074.

31. Schneider G, Krämer OH. NFkappaB/p53 crosstalk-a promising new therapeutic target. Biochim Biophys Acta. 2011; 1815: 90-103.

32. Lane AA, Chabner BA. Histone deacetylase inhibitors in cancer therapy. J Clin Oncol. 2009; 27: 5459-68.

33. Ware RE, Aygun B. Advances in the use of hydroxyurea. Hematology Am Soc Hematol Educ Program. 2009: 62-9.

34. Bolden JE, Peart MJ, Johnstone RW. Anticancer activities of histone deacetylase inhibitors. Nat Rev Drug Discov. 2006; 5: 769-84.

35. Li Y, Kao GD, Garcia BA, Shabanowitz J, Hunt DF, Qin J, Phelan C, Lazar MA. A novel histone deacetylase pathway regulates mitosis by modulating Aurora B kinase activity. Genes Dev. 2006; 20: 2566-79.

36. Blumenschein GR, Jr., Kies MS, Papadimitrakopoulou VA, Lu C, Kumar AJ, Ricker JL, Chiao JH, Chen C, Frankel SR. Phase II trial of the histone deacetylase inhibitor vorinostat (Zolinza, suberoylanilide hydroxamic acid, SAHA) in patients with recurrent and/or metastatic head and neck cancer. Invest New Drugs. 2008; 26: 81-7.

37. Prince HM, Bishton MJ, Harrison SJ. Clinical studies of histone deacetylase inhibitors. Clin Cancer Res. 2009; 15 : 3958-69.

38. Schrump DS. Cytotoxicity mediated by histone deacetylase inhibitors in cancer cells: mechanisms and potential clinical implications. Clin Cancer Res. 2009; 15: 3947-57.

39. Stephens PJ, McBride DJ, Lin ML, Varela I, Pleasance ED, Simpson JT, Stebbings LA, Leroy C, Edkins S, Mudie LJ, Greenman CD, Jia M, Latimer C, Teague JW, Lau KW, Burton J, Quail MA, Swerdlow H, Churcher C, Natrajan R, Sieuwerts AM, Martens JW, Silver DP, Langerod A, Russnes HE, Foekens JA, Reis-Filho JS, van 't Veer L, Richardson AL, Borresen-Dale AL, Campbell PJ, Futreal PA, Stratton MR. Complex landscapes of somatic rearrangement in human breast cancer genomes. Nature. 2009; 462: 1005-10.

40. Atmaca A, Al-Batran SE, Maurer A, Neumann A, Heinzel T, Hentsch B, Schwarz SE, Hövelmann S, Göttlicher M, Knuth A, Jäger E. Valproic acid (VPA) in patients with refractory advanced cancer: a dose escalating phase I clinical trial. Br J Cancer. 2007; 97: 177-82.

41. Bug G, Ritter M, Wassmann B, Schoch C, Heinzel T, Schwarz K, Romanski A, Krämer OH, Kampfmann M, Hoelzer D, Neubauer A, Ruthardt M, Ottmann OG. Clinical trial of valproic acid and all-trans retinoic acid in patients with poor-risk acute myeloid leukemia. Cancer. 2005; 104 : 2717-25.

42. Tan TT, Degenhardt K, Nelson DA, Beaudoin B, NievesNeira W, Bouillet P, Villunger A, Adams JM, White E. Key roles of BIM-driven apoptosis in epithelial tumors and rational chemotherapy. Cancer Cell. 2005; 7: 227-38.

43. Chen S, Dai Y, Pei XY, Grant S. Bim upregulation by histone deacetylase inhibitors mediates interactions with the Bcl-2 antagonist ABT-737: evidence for distinct roles for Bcl-2, Bcl-xL, and Mcl-1. Mol Cell Biol. 2009; 29: 614969.

44. Lu WJ, Amatruda JF, Abrams JM. p53 ancestry: gazing through an evolutionary lens. Nat Rev Cancer. 2009; 9: 758-62.

45. Mishra A, Bharti AC, Saluja D, Das BC. Trans-activation and expression patterns of jun and fos / AP-1 super-family proteins in human oral cancer. Int J Cancer. 2009.

46. Yogev O, Anzi S, Inoue K, Shaulian E. Induction of transcriptionally active Jun proteins regulates drug-induced senescence. J Biol Chem. 2006; 281: 34475-83.

47. Weiss C, Schneider S, Wagner EF, Zhang X, Seto E, Bohmann D. JNK phosphorylation relieves HDAC3dependent suppression of the transcriptional activity of c-Jun. Embo J. 2003; 22: 3686-95.

48. Yan J, Hales BF. p38 and c-Jun N-terminal kinase mitogenactivated protein kinase signaling pathways play distinct roles in the response of organogenesis-stage embryos to a teratogen. J Pharmacol Exp Ther. 2008; 326: 764-72.

49. Poeta ML, Manola J, Goldwasser MA, Forastiere A, Benoit N, Califano JA, Ridge JA, Goodwin J, Kenady D, Saunders 
J, Westra W, Sidransky D, Koch WM. TP53 mutations and survival in squamous-cell carcinoma of the head and neck. N Engl J Med. 2007; 357: 2552-61.

50. Gillenwater AM, Zhong M, Lotan R. Histone deacetylase inhibitor suberoylanilide hydroxamic acid induces apoptosis through both mitochondrial and Fas (Cd95) signaling in head and neck squamous carcinoma cells. Mol Cancer Ther. 2007; 6: 2967-75.

51. Cragg MS, Jansen ES, Cook M, Harris C, Strasser A, Scott CL. Treatment of B-RAF mutant human tumor cells with a MEK inhibitor requires Bim and is enhanced by a $\mathrm{BH} 3$ mimetic. J Clin Invest. 2008; 118: 3651-9.

52. Ruiz-Godoy RL, Garcia-Cuellar CM, Herrera Gonzalez NE, Suchil BL, Perez-Cardenas E, Sacnchez-Perez Y, SuarezRoa ML, Meneses A. Mutational analysis of K-ras and Ras protein expression in larynx squamous cell carcinoma. J Exp Clin Cancer Res. 2006; 25: 73-8.

53. Weber A, Langhanki L, Sommerer F, Markwarth A, Wittekind C, Tannapfel A. Mutations of the BRAF gene in squamous cell carcinoma of the head and neck. Oncogene. 2003; 22: 4757-9.

54. Hoellein A, Pickhard A, von Keitz F, Schoeffmann S, Piontek G, Rudelius M, Baumgart A, Wagenpfeil S, Peschel C, Dechow T, Bier H, Keller U. Aurora kinase inhibition overcomes cetuximab resistance in squamous cell cancer of the head and neck. Oncotarget. 2011; 2: 599-609.

55. Wang X, Wang R, Hao MW, Dong K, Wei SH, Lin F, Ren $\mathrm{JH}$, Zhang HZ. The BH3-only protein PUMA is involved in green tea polyphenol-induced apoptosis in colorectal cancer cell lines. Cancer Biol Ther. 2008; 7: 902-8.

56. Shields BJ, Hauser C, Bukczynska PE, Court NW, Tiganis T. DNA replication stalling attenuates tyrosine kinase signaling to suppress $\mathrm{S}$ phase progression. Cancer Cell. 2008; 14: 166-79.

57. Pennock S, Wang Z. A tale of two Cbls: interplay of $\mathrm{c}-\mathrm{Cbl}$ and Cbl-b in epidermal growth factor receptor downregulation. Mol Cell Biol. 2008; 28: 3020-37.

58. Zhu P, Huber E, Kiefer F, Göttlicher M. Specific and redundant functions of histone deacetylases in regulation of cell cycle and apoptosis. Cell Cycle. 2004; 3: 1240-2.

59. Li N, Sood S, Wang S, Fang M, Wang P, Sun Z, Yang $\mathrm{CS}$, Chen $\mathrm{X}$. Overexpression of 5-lipoxygenase and cyclooxygenase 2 in hamster and human oral cancer and chemopreventive effects of zileuton and celecoxib. Clin Cancer Res. 2005; 11: 2089-96.

60. Schrell UM, Rittig MG, Anders M, Kiesewetter F, Marschalek R, Koch UH, Fahlbusch R. Hydroxyurea for treatment of unresectable and recurrent meningiomas. I. Inhibition of primary human meningioma cells in culture and in meningioma transplants by induction of the apoptotic pathway. J Neurosurg. 1997; 86: 845-52.

61. Fetz V, Bier C, Habtemichael N, Schuon R, Schweitzer A, Kunkel M, Engels K, Kovacs AF, Schneider S, Mann W, Stauber RH, Knauer SK. Inducible NO synthase confers chemoresistance in head and neck cancer by modulating survivin. Int J Cancer. 2009; 124: 2033-41.

62. Krämer $\mathrm{OH}, \mathrm{Knauer} \mathrm{SK}$, Greiner $\mathrm{G}$, Jandt E, Reichardt S, Gührs KH, Stauber RH, Böhmer FD, Heinzel T. A phosphorylation-acetylation switch regulates STAT1 signaling. Genes Dev. 2009; 23: 223-35.

63. Brenner JC, Graham MP, Kumar B, Saunders LM, Kupfer R, Lyons RH, Bradford CR, Carey TE. Genotyping of 73 UM-SCC head and neck squamous cell carcinoma cell lines. Head Neck. 2010; 32: 417-26.

64. Welkoborsky HJ, Jacob R, Riazimand SH, Bernauer HS, Mann WJ. Molecular biologic characteristics of seven new cell lines of squamous cell carcinomas of the head and neck and comparison to fresh tumor tissue. Oncology. 2003; 65: 60-71.

65. Ploner C, Rainer J, Niederegger H, Eduardoff M, Villunger A, Geley S, Kofler R. The BCL2 rheostat in glucocorticoidinduced apoptosis of acute lymphoblastic leukemia. Leukemia. 2008; 22: 370-7.

66. Knauer SK, Bier C, Habtemichael N, Stauber RH. The Survivin-Crm1 interaction is essential for chromosomal passenger complex localization and function. EMBO Rep. 2006; 7: 1259-65.

67. Knauer SK, Krämer OH, Knösel T, Engels K, Rodel F, Kovacs AF, Dietmaier W, Klein-Hitpass L, Habtemichael N, Schweitzer A, Brieger J, Rödel C, Mann W, Petersen I, Heinzel T, Stauber RH. Nuclear export is essential for the tumor-promoting activity of survivin. Faseb J. 2007; 21: 207-16.

68. Knauer SK, Bier C, Schlag P, Fritzmann J, Dietmaier W, Rodel F, Klein-Hitpass L, Kovacs AF, Doring C, Hansmann ML, Hofmann WK, Kunkel M, Brochhausen C, Engels K, Lippert BM, Mann W, Stauber RH. The survivin isoform survivin-3B is cytoprotective and can function as a chromosomal passenger complex protein. Cell Cycle. 2007; 6: 1502-9.

69. Stauber RH, Rabenhorst U, Rekik A, Engels K, Bier C, Knauer SK. Nucleocytoplasmic shuttling and the biological activity of mouse survivin are regulated by an active nuclear export signal. Traffic. 2006; 7: 1461-72.

70. Zantl N, Weirich G, Zall H, Seiffert BM, Fischer SF, Kirschnek S, Hartmann C, Fritsch RM, Gillissen B, Daniel PT, Hacker G. Frequent loss of expression of the proapoptotic protein Bim in renal cell carcinoma: evidence for contribution to apoptosis resistance. Oncogene. 2007; 26: 7038-48. 